\title{
Alcohol use disorders in the emergency ward: choice of the best mode of assessment and identification of at-risk situations
}

\author{
Charlotte Richoux ${ }^{1,2}$, Isabelle Ferrand ${ }^{3}$, Enrique Casalino ${ }^{4}$, Benoit Fleury ${ }^{5}$, Christine Ginsburg ${ }^{6}$ and \\ Michel Lejoyeux ${ }^{1,2^{*}}$
}

\begin{abstract}
Background: This study aims to identify the prevalence and at-risk situations of alcohol use disorders among patients examined in the emergency department and to compare the scales commonly used to identify alcohol use disorders.

Methods: We used the CAGE and AUDIT questionnaires and a structured interview, the MINI.

Findings: Of the presenting patients, 9.5\% met the DSM-IV criteria for alcohol use disorders. The CAGE questionnaire was less sensitive (75\%) and more specific (92\%) than the AUDIT (87 and 80\%, respectively). The typical alcohol-dependent patient is a young man who is unemployed and brought to the emergency department by the police. During the past $24 \mathrm{~h}$, he has consumed alcohol, nicotine, cocaine, sedatives or cannabis.

Conclusion: Of the patients, 9.5\% examined in the emergency department present with alcohol abuse or dependence without asking spontaneously for treatment for their addiction. These results support the importance of systematically identifying alcohol use disorders with a simple and rapid questionnaire such as the CAGE questionnaire.
\end{abstract}

\section{Introduction}

Alcohol use disorders are one of the most frequent diagnoses among patients examined in an emergency ward [1]. D'onofrio et al. noticed that $25 \%$ of the people admitted to an emergency ward showed misuse of alcohol [2]. Despite this high frequency rate, alcohol use disorders are usually not diagnosed in the emergency ward [2], and patients do not ask for specific help related to alcohol.

\section{Aim of the study}

Our work had two objectives

- To compare the acceptability and utility of two commonly used clinical scales, the CAGE [3] and AUDIT (Alcohol Use Disorders Identification Test) [4], to a structured clinical interview, the Mini International Neuropsychiatric Interview (MINI) [5], checking the DSMIV-TR (Diagnostic and Statistical Manual of Mental

\footnotetext{
* Correspondence: michel.lejoyeux@bch.aphp.fr

${ }^{1}$ Hopital Maison Blanche, Paris, France

Full list of author information is available at the end of the article
}

Disorders, Fourth Edition revised) [6] criteria for alcohol abuse and dependence,

- To identify at-risk situations for alcohol use disorders.

\section{Methods}

All participants aged 18 years and over presented to one of the three French emergency wards participating in the study (Bichat, Cochin-Paris and Saint-André-Bordeaux). Each year Bichat hospital receives 80,000 medical, surgical and psychiatric emergency patients from the northern districts of Paris. Cochin Hospital receives 47,000 emergency patients each year from the center of Paris and Bordeaux Hospital 22,000 each year.

Over a 6-month period (September 2008 to March 2009), we interviewed 1,079 consecutive patients, equally divided among the three wards. Interviews were conducted between 9 a.m. and 7 p.m. by the same investigator (C.R.). We proposed the assessment to all consecutive patients presenting to the emergency ward during the study period.

\section{SpringerOpen ${ }^{\circ}$}

(C) 2011 Richoux et al; licensee Springer. This is an Open Access article distributed under the terms of the Creative Commons Attribution License (http://creativecommons.org/licenses/by/2.0), which permits unrestricted use, distribution, and reproduction in any medium, provided the original work is properly cited. 
We did pre-select the patients. Because of the severity of their somatic states (extreme pain, shell-shocked, needing intensive reanimation), 100 patients who couldn't answer the questionnaire were not included. Among the patients not included, 15 were unable to participate because of too high alcohol consumption. All other patients in a state of inebriation were assessed when their alcohol level decreased and when they were sufficiently alert to understand the questionnaire. Globally, $1 \%$ of patients were not included, and $0.1 \%$ (19) refused to answer the questionnaire.

Our work was presented to and approved by the ethics committee of our department. All patients participated voluntarily in the study. To ensure confidentiality, all identifying data were removed, and records were kept under lock and key. Written informed consent was obtained.

\section{Sociological and demographic characteristics, medical history and psychiatric status}

We collected demographic details (sex, age, work and family status) with a specific, previously validated questionnaire [7]. We noted the mode of access to the emergency department, the type of emergency, and the number of consultations and hospitalizations during the last year.

Alcohol, nicotine and cannabis consumption, abuse and dependence, behavioral addiction

We checked the DSM-IV-TR diagnostic criteria for alcohol abuse and dependence with a specific section of the Mini International Neuropsychiatric Interview (MINI). We also used the AUDIT scale and the CAGE Questionnaire. AUDIT is a 10-item questionnaire used to screen for alcohol misuse disorder. A score of 8 or more indicates an alcohol use disorder. The CAGE is a 4-item screening tool. A score of 2 or more indicates an alcohol use disorder.

\section{Questions on the CAGE questionnaire}

C Have you ever felt you should cut down on your drinking?

A Have people annoyed you by criticizing your drinking?

G Have you ever felt bad or guilty about your drinking?

E Have you ever had a drink first thing in the morning to steady your nerves or get rid of a hangover (eyeopener)?

\section{AUDIT Questionnaire}

1. How often do you have a drink containing alcohol?

Never
Monthly or less

2-4 times a month

2-3 times a week

4 or more times a week

2. How many standard drinks containing alcohol do you have on a typical day when drinking?

1 or 2

3 or 4

5 or 6

7 to 9

10 or more

3. How often do you have six or more drinks on one occasion?

Never

Less than monthly

Monthly

Weekly

Daily or almost daily

4. During the past year, how often have you found that you were not able to stop drinking once you had started?

Never

Less than monthly

Monthly

Weekly

Daily or almost daily

5. During the past year, how often have you failed to do what was normally expected of you because of drinking?

Never

Less than monthly

Monthly

Weekly

Daily or almost daily

6. During the past year, how often have you needed a drink in the morning to get yourself going after a heavy drinking session?

Never

Less than monthly

Monthly

Weekly

Daily or almost daily

7. During the past year, how often have you had a feeling of guilt or remorse after drinking?

Never

Less than monthly

Monthly

Weekly

Daily or almost daily

8. During the past year, have you been unable to remember what happened the night before because you had been drinking?

Never

Less than monthly 
Monthly

Weekly

Daily or almost daily

9. Have you or someone else been injured as a result of your drinking?

No

Yes, but not in the past year

Yes, during the past year

10. Has a relative or friend, doctor or other health worker been concerned about your drinking or suggested you cut down?

No

Yes, but not in the past year

Yes, during the past year

We studied the sensitivity and specificity of these two scales by comparing the number of patients that they identified as presenting an alcohol disorder. Using a standardized questionnaire [7], we quantified the number of drinks taken each day. A drink was defined as the amount of alcohol (10 g) found in $300 \mathrm{ml}$ of beer, $100 \mathrm{ml}$ of wine or $25 \mathrm{ml}$ of whisky. Cigarette smoking was studied with the Fagerström questionnaire [8] and the DSM-IV-TR criteria for nicotine dependence. Lastly, we checked the DSM-IV-TR criteria for nicotine, opiates, cocaine, sedatives and cannabis abuse and dependence [9].

\section{Statistical Analysis}

\section{Statistical methods}

We used Student's $t$-test to compare continuous variables. For categorical data, we studied differences between proportions with the multiple $\chi^{2}$-test. Statistical significance was determined at the 0.05 level of confidence.

\section{Results}

Comparison of acceptability, sensitivity and specificity of the CAGE and AUDIT questionnaires

The standardized MINI interview showed that $9.5 \%$ of the patients $(N=103)$ presented misuse with alcohol abuse or dependence disorders. The CAGE questionnaire identified alcohol problems in $6.1 \%$ of the 1,079 patients examined in the emergency department, and the AUDIT scale showed a prevalence rate for alcohol use disorders of $9.4 \%$. Considering the DSM-IV-R criteria diagnosis as a reference, we found that the CAGE questionnaire identified 77 true-positive and 897 truenegative cases, and the AUDIT 90 true-positive and 780 true-negative cases. The sensitivity (true-positive cases) of the CAGE questionnaire was $75 \%$ (77/103). The AUDIT sensitivity rate was higher at $87 \%(90 / 103)$. The CAGE questionnaire had a higher rate of specificity [true-negative cases; 92\% (897/976)] than the AUDIT [80\% (780/976)].
Identification of patients at-risk for alcohol use disorders We compared patients identified as alcohol abusers or dependent with the MINI questionnaire and with the DSM-IV-TR criteria (Alcohol + group) to those who did not fulfill these criteria (Alcohol - group). Forty-one percent had been previously treated for alcohol use disorders, and $23 \%$ hospitalized for a reason directly related to alcohol abuse or dependence. Patients from the Alcohol + group were younger, and the ratio of men was higher. They were more often unemployed, had taken more days of sick leave during the last year (3.3 versus 1.6 days, respectively) and were more often brought to the emergency department by police. Alcohol + patients drank larger amounts of alcohol and presented more often with acute intoxication. They smoked more cigarettes and more often demonstrated cannabis, opiate, cocaine and sedative dependence (tables 1 and 2).

\section{Discussion}

\section{Comparison of modes of assessment}

The AUDIT questionnaire was more sensitive than the CAGE, which however allowed the identification of $75 \%$ of patients with alcohol use disorders. When the CAGE questionnaire is given without explanation by a nurse or a doctor in another context, answers to its four questions may be less accurate. The CAGE questionnaire is thus recommended to be delivered by a nurse or a doctor specifically competent in the recognition of addiction. However, the AUDIT questionnaire is still the more sensitive instrument (92\% versus $75 \%$ ), even if it takes more time to complete.

\section{At-risk situations for alcohol abuse or dependence among patients examined in the emergency department}

The typical patient presenting to the emergency department with an alcohol use disorder is a young, unemployed man, usually brought to the emergency department by the police or examined after a state of agitation. During the past $24 \mathrm{~h}$, he has consumed alcohol, nicotine or cannabis. He has more often been treated for alcohol abuse or dependence by a general practitioner or a specialist. In one case of four, he has been hospitalized for alcohol use disorders, and he has had more days of sick leave during the last year. He presents dependence or abuse of nicotine, cannabis, opiates, cocaine or sedatives more often.

\section{Consequences of the results for clinical practice and public health}

None of the patients identified as an abuser of or dependent on alcohol had asked for specific help for addiction before being diagnosed by our systematic intervention. If they had not been assessed, they would have left the emergency ward with no treatment or information about 
Table 1 Socio-demographic and addictive characteristics of patients examined in an emergency ward presenting with and without alcohol use disorders

\begin{tabular}{|c|c|c|c|c|}
\hline & $\begin{array}{l}\text { Alcohol use } \\
\text { disorders } \\
N=103\end{array}$ & $\begin{array}{l}\text { Non-alcohol use } \\
\text { disorders } \\
N=976\end{array}$ & $\begin{array}{l}\text { All patients } \\
N=1,079\end{array}$ & Statistics \\
\hline Age: mean (SD) & $42.7(15)$ & $47(20)$ & $46.6(20)$ & Student's $t=-2$ \\
\hline Range & $18-74$ & 18-94 & $18-94$ & $\mathrm{df}=1,077, p=0.01$ \\
\hline \multicolumn{5}{|l|}{ Gender } \\
\hline Men & $61(59 \%)$ & $432(45 \%)$ & $493(46 \%)$ & $\chi^{2}=8.4, d f=1, p=0.004$ \\
\hline Women & $42(41 \%)$ & $544(55 \%)$ & $586(54 \%)$ & $\chi^{2}=8.4, d f=1, p=0.004$ \\
\hline \multicolumn{5}{|l|}{ Work status } \\
\hline Working & $53(51 \%)$ & $563(58 \%)$ & $616(57 \%)$ & $\chi^{2}=1.4, d f=1, p=0.22$ \\
\hline Unemployed & $13(13 \%)$ & $63(6 \%)$ & $76(7 \%)$ & $\chi^{2}=5.4, \mathrm{df}=1, p=0.02$ \\
\hline $\begin{array}{l}\text { Days of sick leave mean (SD) in } \\
\text { the year }\end{array}$ & $3.3(3.9)$ & $1.6(20.6)$ & $3.2(19)$ & $\begin{array}{l}\text { Student's } t=-2, \mathrm{df}=1,077 \\
p=0.38\end{array}$ \\
\hline \multicolumn{5}{|l|}{ Family } \\
\hline Lives alone & $57(55 \%)$ & $560(57 \%)$ & $617(55 \%)$ & $\chi^{2}=0.1, \mathrm{df}=1, p=0.7$ \\
\hline Lives in family & $46(44 \%)$ & $416(42 \%)$ & $462(42 \%)$ & $\chi^{2}=0.1, d f=1, p=0.7$ \\
\hline \multicolumn{5}{|c|}{ Consumption of psycho-active agents during the day of assessment in the emergency ward } \\
\hline Alcohol & $64(62 \%)$ & $93(9.5 \%)$ & $157(14.5 \%)$ & $\chi^{2}=203, \mathrm{df}=1, p<0.0001$ \\
\hline Nicotine & $73(70 \%)$ & $270(27 \%)$ & $343(31 \%)$ & $\chi^{2}=78, d f=1, p<0.0001$ \\
\hline Cannabis & $10(10 \%)$ & $19(2 \%)$ & $29(3 \%)$ & $\chi^{2}=21.4, \mathrm{df}=1, p<0.0001$ \\
\hline Other drugs & $8(8 \%)$ & $1(0.1 \%)$ & $9(1 \%)$ & $\chi^{2}=66, d f=1, p<0.0001$ \\
\hline \multicolumn{5}{|l|}{ Alcoholic drinks } \\
\hline \multicolumn{5}{|l|}{ Number of drinks } \\
\hline during weekdays Mean (SD) & $19.3(18)$ & $1.6(3.5)$ & $3.3(2.5)$ & $\begin{array}{l}\text { Student's } t=25.5, \mathrm{df}=1,077, \\
p<0.0001\end{array}$ \\
\hline $\begin{array}{l}\text { Drinks on weekend Mean } \\
\text { (SD) }\end{array}$ & $11.9(11)$ & $1.3(8)$ & $2.3(2.2)$ & $\begin{array}{l}\text { Student's } t=23.6, \mathrm{df}=1077 \\
p<0.0001\end{array}$ \\
\hline $\begin{array}{l}\text { Drinks all week Mean (SD) } \\
17.8(20)\end{array}$ & $1.5(3)$ & $3.1(3)$ & $\begin{array}{l}\text { Student's } t=21.9, \mathrm{df}=1,077, \\
p<0.0001\end{array}$ & \\
\hline
\end{tabular}

Table 2 Addictive characteristics of patients examined in an emergency ward presenting with and without alcohol use disorders

$\begin{array}{llll}\begin{array}{l}\text { Alcohol use } \\ \text { disorders }\end{array} & \begin{array}{l}\text { Non-alcohol use } \\ \text { disorders }\end{array} & \begin{array}{l}\text { All patients } \\ N=1,079\end{array} & \text { Statistics } \\ N=103 & N=976 & & \end{array}$

Acute alcohol intoxication

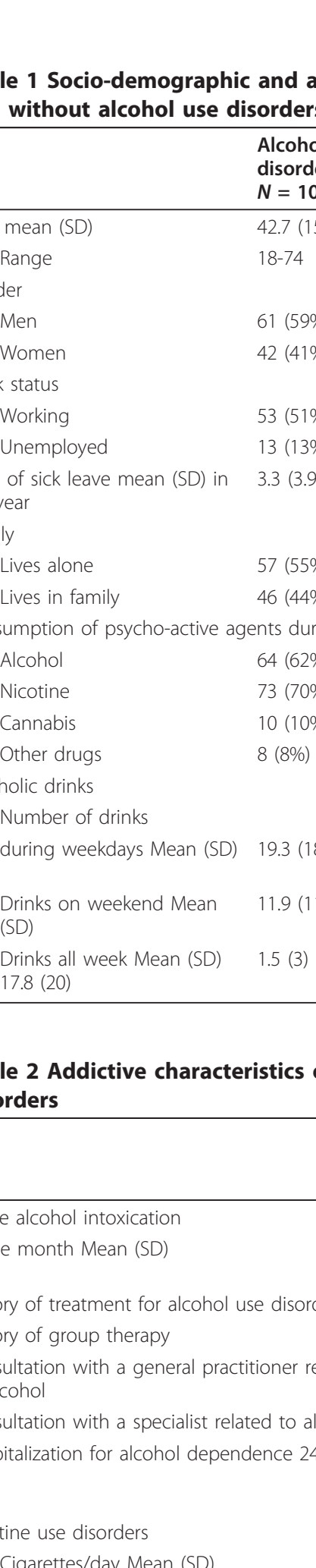

In the month Mean (SD)

$\begin{array}{ll}11.8(12) & 0.2(0.6) \\ 41(39 \%) & 30(3 \%) \\ 19(19 \%) & 13(1 \%) \\ 42(41 \%) & 22(2 \%) \\ 39(38 \%) & 27(3 \%) \\ 9(1 \%) & 33(3 \%)\end{array}$

Nicotine use disorders

Cigarettes/day Mean (SD)

$13.4(11) \quad 5(8)$

$1.3(2.4)$

$\chi^{2}=157, \mathrm{df}=$ $p<0.000$

Fagerström score Mean (SD)

$3.6(3)$

Cannabis abuse

Cannabis dependence
$11(10 \%)$

$6(6 \%)$

$3(0.3 \%)$

$4(0.4 \%)$
$1.3(3.8)$

$71(6 \%)$

$32(3 \%)$

$64(6 \%)$

$66(6 \%)$

1,

Student's $t=28, \mathrm{df}=1,077, p<$ 0.0001

$\chi^{2}=198, d f=1, p<0.0001$

$\chi^{2}=94, \mathrm{df}=1, p<0.0001$

$\chi^{2}=247, \mathrm{df}=1, p<0.0001$

$\chi^{2}=199, \mathrm{df}=1, p<0.0001$

$5.8(9)$

$1.5(2.6)$

Student's $t=8.3, \mathrm{df}=1,077, p<$ 0.0001

Student's $t=8.9, \mathrm{df}=1,077, p<$ 0.0001

$14(1.3 \%)$

$10(1 \%) \quad \chi^{2}=109, \mathrm{df}=2, p<0.0001$ 
Table 2 Addictive characteristics of patients examined in an emergency ward presenting with and without alcohol use disorders (Continued)

\begin{tabular}{|c|c|c|c|c|}
\hline \multicolumn{5}{|l|}{ Opiates use disorders } \\
\hline Opiate abuse & $3(2.9 \%)$ & 0 & $3(0.3 \%)$ & \\
\hline Opiate dependence & $1(1 \%)$ & 0 & $1(0.1 \%)$ & $\chi^{2}=38, \mathrm{df}=2, p<0.0001$ \\
\hline Cocaine abuse & $8(7.7 \%)$ & $1(0.1 \%)$ & $9(0.8 \%)$ & \\
\hline Cocaine dependence & $1(1 \%)$ & $1(0.1 \%)$ & $2(0.2 \%)$ & $\chi^{2}=70, \mathrm{df}=2, p<0.0001$ \\
\hline \multicolumn{5}{|l|}{ Sedative use disorders } \\
\hline Sedative abuse & $9(9 \%)$ & $7(0.7 \%)$ & $16(1.5 \%)$ & \\
\hline Sedative dependence & $8(8 \%)$ & 0 & $8(0.7 \%)$ & $\chi^{2}=118, \mathrm{df}=2, p<0.0001$ \\
\hline
\end{tabular}

the possibilities of help. The stay in the emergency ward represents the only opportunity to receive information and begin to benefit from adequate treatment.

\section{Limitations of the study}

One of the principal limitations of our study is the exclusion of 15 patients unable to answer the questionnaire because of their high level of alcohol intoxication. Another limitation is that our results were only drawn from patients presenting to the emergency ward between 9 a.m. and 9 p.m. Our work is only based on clinical assessment without biological confirmation. In spite of these limitations, our study was the first to include such a high number of patients examined in three French emergency wards and to assess simultaneously all types of dependence.

\section{Conclusion}

Of the patients examined in the emergency department, 9.5\% met the DSM-IV-R criteria of alcohol use disorders. In the context of an emergency, the CAGE questionnaire was less sensitive (75\% versus $87 \%$ ) than the AUDIT scale and more specific ( $92 \%$ versus $87 \%$ ). None of the patients identified as alcohol abusers or dependent made a spontaneous request for treatment. Patients with alcohol disorders were more often men, younger, referred to the emergency ward after a crisis and agitation, and were brought in by the police. They presented a multi-addictive disorder associating nicotine, cannabis, opiate and sedative dependence disorders. These data support the importance of systematically identifying alcohol use disorders in the emergency department and initiating treatment for these patients who would have remained unknown without a specific assessment.

\section{Acknowledgements}

This work was supported by a grant from the Société Française d'Alcoologie.

\section{Author details}

${ }^{1}$ Hopital Maison Blanche, Paris, France ${ }^{2}$ Department of Psychiatry. Hopital Bichat. AP-HP Paris, France ${ }^{3}$ Department of Psychiatry. Hopital Cochin. AP-HP. Paris, France ${ }^{4}$ Emergency ward. Hopital Bichat. AP-HP. Paris, France
${ }^{5}$ Emergency ward. Centre hospitalier universitaire. Bordeaux, France ${ }^{6}$ Emergency ward. Hopital Cochin. AP-HP. Paris, France

\section{Authors' contributions}

$M L, I F$ and CR conceived the study. CR assessed all patients. EC assessed patients in BH, BF in Bordeaux hospital and CG in Cochin Hospital. All authors read and approved the final manuscript.

\section{Competing interests}

The authors declare that they have no competing interests.

Received: 17 November 2010 Accepted: 14 June 2011

Published: 14 June 2011

\section{References}

1. Nordqvist C, Johansson $K$, Bendtsen P: Routine screening for risky alcohol consumption at an emergency department using the AUDIT-C questionnaire. Drug Alcohol Dependence 2003, 74:71-5.

2. D'onofrio G, Becker B, Woolard R: The impact of alcohol, tobacco and other drug use and abuse in the emergency department. Emerg Med Clin North Am 2006, 26:925-67.

3. Ewing JA: Detecting alcoholism: the CAGE questionnaire. JAMA 1984, 252:1905-7.

4. Saunder JB, Aasland OG, Babor TF, de la Fuente JR, Grant M: Development of the alcohol use disorders identification test (AUDIT): WHO collaborative project on early detection of persons with harmful alcohol consumption. Addiction 1993, 88:791-804.

5. Sheehan DV, Lecrubier $Y$, Harnett Sheehan $K$, et al: The validity of the Mini International Neuropsychiatric Interview (MINI) according to the SCID-P and its reliability. Eur Psychiatry 1997, 12:232-241.

6. American Psychiatric Association: Diagnostic and statistical manual of mental disorders. Washington DC; 42000.

7. Saliou V, Fichelle A, McLoughlin M, Thauvin I, Lejoyeux M: Psychiatric disorders among patients admitted to a French medical emergency service. General Hospital Psychiatry 2005, 27:263-8.

8. Fagerström $\mathrm{KO}$, Schneider NG: Measuring nicotine dependence: a review of the Fagerström Tolerance Questionnaire. J Behav Med 1989, 12:159-82.

9. Lejoyeux M, Feuché N, Loi S, Solomon J, Adès J: Study of impulse control disorders among alcohol-dependent patients. J Clin Psychiatry 1999, 40(5):302-305.

doi:10.1186/1865-1380-4-27

Cite this article as: Richoux et al:: Alcohol use disorders in the emergency ward: choice of the best mode of assessment and identification of at-risk situations. International Journal of Emergency Medicine 2011 4:27. 